\title{
La creación y la adaptación de material didáctico para las clases virtuales de ELE en el contexto de la COVID-19
}

\author{
Creating and Adapting Teaching Material for ELE Virtual Lessons \\ in the Context of COVID-19
}

\author{
LORENA EMILSE CIOCCOLANTI \\ Profesora / Formadora de ElE EN AC. XPANISH \\ (Centro de español como lengua extranjera en Córdoba, ARgentina) \\ Icioccolanti@hotmail.com
}

\begin{abstract}
Resumen
Este artículo presenta los resultados de un estudio sobre la creación y la adaptación de material didáctico para la clase virtual de ELE en el contexto de la COVID-19. Por un lado, se exponen los resultados obtenidos al pilotar un corpus lingüístico de material didáctico digital. Por el otro, los datos recabados de una investigación de corte cuantitativo, cuyo instrumento de recolección consistió en un cuestionario en línea, dirigido a profesores del sector. De acuerdo con los resultados, la adaptación del material didáctico fue percibida como un asunto problemático, siendo la falta de tiempo la principal limitación.
\end{abstract}

Palabras clave: español como lengua extranjera o segunda (ELE/EL2), clases en línea y en vivo, creación o adaptación de material didáctico, herramientas digitales, COVID-19

\footnotetext{
Abstract

This article presents the results of a study on the creation and adaptation of teaching material for ELE virtual lessons in the context of COVID-19. It shows, on the one hand, the results obtained after piloting a linguistic corpus of digital teaching materials; on the other, the data collected from quantitative research, for which an online survey was used as a data collection instrument, addressed to teachers in the field. According to the results, the adaptation of this material was perceived as a problematic issue, with time constraints being the main limitation.

Keywords: Spanish as a Foreign or Second Language (ELE/EL2), online and live lessons, creation or adaptation of teaching material, digital tools, COVID-19
} 


\section{Introducción}

Después del 11 de marzo de 2020, fecha en que la Organización Mundial de la Salud (OMS), concluyera en su evaluación de que la COVID-19 se considerara pandemia ${ }^{1}$ debido a los alarmantes niveles de propagación y gravedad $^{2}$ (OMS, 2020), el mundo entero empezó a cambiar y el campo de la enseñanza del español como lengua extranjera no fue ajeno a esa realidad.

Debido a las circunstancias, y dado que en una gran cantidad de países comenzaba a regir un confinamiento o cuarentena estricta, y en otros, una serie de normas de convivencia social y seguridad sanitaria incompatibles con el dictado de clases presenciales, hubo una necesidad imperiosa e inmediata de transformar los $\operatorname{cursos}^{3}$ de español presenciales en cursos en línea y en vivo en un tiempo récord ${ }^{4}$. Digitalizar el modelo presencial a través del dictado de clases de esta naturaleza fue, para un gran número de profesores autónomos e instituciones, la única opción viable en el contexto dado.

Los docentes de ELE (Español como Lengua Extranjera), sin contar los libros que normalmente utilizamos en clase, estamos acostumbrados a llevar al aula un sinfín de materiales extra y una gran variedad de recursos para dinamizar nuestras clases, como tarjetas, tableros y juegos, entre otros. Por este motivo, el objetivo de este artículo es dar respuesta a los siguientes interrogantes: ¿existen diferencias entre el material que se utiliza para impartir las clases presenciales y el material que se usa para las clases en línea? ¿Puede crearse o adaptarse cualquier tipo de actividad? ¿Cuáles son las posibilidades tecnológicas con las que contamos? ¿Cuáles son las principales limitaciones a las que nos enfrentamos? ¿Estábamos los docentes de ELE preparados para tal desafío?

Para ello, se confeccionó un corpus de material didáctico para su estudio y una encuesta en línea dirigida a profesionales del sector. La investigación se llevó a cabo en el marco de una pequeña escuela de español

\footnotetext{
${ }^{1}$ El director general de la OMS en su alocución de apertura en la rueda de prensa sobre la COVID-19 celebrada el 11 de marzo de 2020 expresa: “[...] hemos llegado a la conclusión de que la COVID-19 puede considerarse una pandemia. [...]".

2 En esa misma alocución se menciona: "A lo largo de las dos últimas semanas, el número de casos de COVID-19 fuera de China se ha multiplicado por 13, y el número de países afectados se ha triplicado. [...] estamos profundamente preocupados tanto por los alarmantes niveles de propagación y gravedad [...]".

3 A los fines de este artículo, se entiende por cursos, tanto un conjunto de clases, generalmente presentadas en forma de paquete, como clases ofrecidas de manera individual.

${ }^{4}$ Desde que la OMS dictamina la pandemia (11 de marzo de 2020) hasta que en países como España, por ejemplo, decretan algún tipo de confinamiento (14 de marzo de 2020), transcurre un periodo de tan solo 72 horas. Fuente: https://www.boe.es/boe/dias/2020/03/14/pdfs/BOE-A-2020-3692.pdf
} 
para extranjeros que dicta cursos de español en un contexto de inmersión lingüística 5 .

\section{Qué se entiende por material}

Para los fines del presente artículo se entiende por material tanto a secuencias didácticas como z ejercicios aislados ${ }^{6}$ que utiliza un profesor en sus clases con el propósito de conseguir algún tipo de objetivo en el proceso de enseñanza-aprendizaje de la lengua.

De acuerdo con la definición proporcionada por el Centro Virtual Cervantes en su Diccionario de términos clave de ELE, "se entiende por secuencia didáctica una serie ordenada de actividades relacionadas entre sí. Esta serie de actividades, que pretende enseñar un conjunto determinado de contenidos, puede constituir una tarea ${ }^{7}$, una lección ${ }^{8}$ completa o una parte de esta". Con respecto al término "ejercicio», se tomó la definición propuesta por Martín Peris (1996: 343): “unidad mínima independiente de actuación discente, para realizar en el aula o fuera de ella".

Para los propósitos de esta investigación, de ahora en adelante, y contemplando las definiciones que se acaban de exponer, se adoptarán los siguientes términos como equivalentes: «secuencia didáctica» y «lección»; "ejercicio» y «actividad».

Cabe aclarar que, por un lado, dichas secuencias didácticas o ejercicios se pueden crear con herramientas informáticas, utilizar en línea o descargar de algún sitio web; en este caso ya se contaría con una versión digital de los archivos. Por otro lado, en el caso del material físico como fotocopias, se puede digitalizar tipeándolo o escaneándolo para llevarlo a una clase en línea.

\footnotetext{
${ }^{5}$ Por cursos de español en un contexto de inmersión lingüística, se entiende a los ofrecidos por escuelas de español para extranjeros, academias de idiomas, universidades, otros centros de estudios y organismos $u$ organizaciones radicados en países hispanos. Los alumnos que se matriculan para tomar este tipo de cursos son estudiantes internacionales y provienen, en su gran mayoría, de países no hispanohablantes, cuya lengua materna es cualquier idioma excepto el español.

${ }^{6}$ Se consideran ejercicios aislados a aquellos que no están vinculados con otros.

7 “El enfoque por tareas es la propuesta de un programa de aprendizaje de lengua cuyas unidades consisten en actividades de uso de la lengua, [...]. Su objetivo es fomentar el aprendizaje mediante el uso real de la lengua en el aula [...]". Véase la definición completa del término en el Diccionario de términos clave de ELE (CVC) «Enfoque por tareas»: https://cvc.cervantes.es/ensenanza/biblioteca ele/diccio ele/diccionario/enfoquetareas. htm

8 "Por lección se entiende el conjunto de acciones pedagógicas del profesor con las que pretende que los alumnos aprendan algo en el aula. [...]. El término lección también se refiere a la unidad básica en que se organizan los manuales para la enseñanza de lenguas. [...]". Véase la definición completa del término en el Diccionario de términos clave de ELE (CVC) «Lección»:

https://cvc.cervantes.es/ensenanza/biblioteca ele/diccio ele/diccionario/leccion.htm
} 


\section{Metodología}

La metodología utilizada se divide en dos partes. Por un lado, el diseño y pilotaje de un corpus de material didáctico con el fin de realizar todas las pruebas técnicas pertinentes para dar respuesta a las preguntas planteadas al inicio de este artículo.

Por otro lado, un cuestionario en línea, mayormente cuantitativo, dirigido a profesionales del sector para recabar información de primera mano de los docentes de ELE. El objetivo de dicho cuestionario es cotejar los resultados con los obtenidos al estudiar el corpus lingüístico y así aumentar el grado de fiabilidad de los resultados.

\section{Corpus lingüístico}

En este apartado, en primer lugar, se brindarán detalles del corpus lingüístico y su pilotaje. Luego, se describirá el procedimiento utilizado para su creación y adaptación. Posteriormente, se explicará de manera breve cómo trasladar juegos tradicionales e incorporarlos en una clase virtual.

\subsection{Elaboración y puesta a prueba del corpus lingüístico}

Se elaboró un corpus de material didáctico digital compuesto por un conjunto de 10 secuencias didácticas y un total de 212 ejercicios (véase Imagen 1), correspondientes al nivel $A 1^{9}$ "Acceso» del Marco Común Europeo de Referencia para las Lenguas (MCER). El corpus incluye, por un lado, material didáctico propio creado con herramientas digitales $y$, por el otro, material didáctico adaptado de otros recursos físicos y virtuales.

Imagen 1. Corpus lingüístico

\begin{tabular}{|l|c|}
\hline $\begin{array}{c}\text { SECUENCIAS } \\
\text { DIDACTICAS }\end{array}$ & $\begin{array}{c}\text { CANTIDAD DE } \\
\text { EJERCICIOS }\end{array}$ \\
\hline Secuencia didáctica 1 & 22 \\
\hline Secuencia didáctica 2 & 22 \\
\hline Secuencia didáctica 3 & 12 \\
\hline Secuencia didáctica 4 & 21 \\
\hline Secuencia didáctica 5 & 26 \\
\hline Secuencia didáctica 6 & 17 \\
\hline Secuencia didáctica 7 & 15 \\
\hline Secuencia didáctica 8 & 22 \\
\hline Secuencia didáctica 9 & 27 \\
\hline Secuencia didáctica 10 & 28 \\
\hline TOTAL EJERCICIOS & 212 \\
\hline
\end{tabular}

Fuente: elaboración propia

\footnotetext{
${ }^{9}$ Para una descripción detallada de este nivel, véase A1 en «Cuadro 1. Niveles comunes de referencia: escala global», en el MCER (Consejo de Europa, 2002: 26).
} 
Cada secuencia didáctica gira en torno a un tema (la clase, la casa, la familia, etc.) y abarca un conjunto de funciones de la lengua propuestas por el Plan Curricular del Instituto Cervantes (PCIC) (véase Littlewood, 1998, capítulo 7 e Instituto Cervantes, 2006). Dichos temas y funciones se ordenaron de acuerdo con el dominio (nulo, menor o mayor) de la lengua que se prevé que poseen los estudiantes en cada una de las secuencias. Por otra parte, cada secuencia didáctica contempla tanto actividades de gramática, pronunciación y vocabulario como una serie de actividades comunicativas que incluyen las distintas destrezas lingüísticas ${ }^{10}$, tal como se propone en el MCER (véase capítulo 4.4.). Asimismo, con el propósito de gamificar las clases, algunos ejercicios tienen un formato de actividades lúdicas o juegos.

Cabe aclarar que los audios o videos correspondientes a las actividades de pronunciación, de comprensión auditiva o audiovisual no se crearon ni se adaptaron, puesto que no era necesario, sino que se reprodujeron a través del mismo dispositivo utilizado para impartir las clases en línea. En otras palabras, los audios o videos no son de creación propia sino de terceros.

Por cuestiones de necesidad y urgencia debido a la pandemia, el corpus se comenzó a elaborar y probar casi en simultáneo a mediados de marzo de 2020, lo que coincide con el traspaso de las clases de español presenciales a las clases en línea. Las últimas actividades se terminaron de realizar y poner a prueba a finales de julio de 2021, lo que suma un total de un año y cuatro meses de trabajo.

La ejecución y puesta en práctica se llevó a cabo por dos profesoras nativas: una de ellas con amplia experiencia en la enseñanza de español en un contexto de inmersión lingüística (14 años) y, la otra, con tres años de experiencia. Ninguna había impartido clases de español en línea con anterioridad.

Las clases se dictaron en forma particular a cuatro estudiantes mayores de edad de diferentes edades y nacionalidades, a través de un programa de videoconferencia ${ }^{11}$. Si bien cada estudiante eligió la frecuencia y la duración de las clases, en general, optaron por tener clases dos o tres veces por semana con una duración de entre una hora y una hora y media cada clase.

Cabe destacar que otros profesores utilizaron el corpus de estudio para impartir clases a otros estudiantes e hicieron valiosas aportaciones. No obstante, las dos profesoras mencionadas con anterioridad fueron las encargadas de probar minuciosamente cada una de las actividades, sugerir posibles cambios y aplicar aquellos que de mutuo acuerdo consideraban pertinentes, según las observaciones realizadas.

\footnotetext{
10 Expresión oral, expresión escrita, comprensión auditiva, comprensión de lectura y comprensión audiovisual.

${ }^{11}$ Se utilizó Zoom por poseer algunas características que lo diferencian del resto, resultando de esa manera ser más adecuado en función de determinadas necesidades, intereses y preferencias. Sin embargo, otros programas de videoconferencia son igualmente válidos para tal fin. Enlace: https://zoom.us/
} 


\subsection{Procedimiento para la creación y la adaptación del material}

Para la elaboración del corpus de material didáctico digital se utilizó principalmente un procesador de texto (Microsoft Word) y una herramienta de diseño (Canva) ${ }^{12}$. Con el primero, se crearon y se adaptaron ejercicios (tanto desde un soporte físico como digital) para conformar secuencias didácticas contenidas en un único documento; y con la segunda, se diseñaron presentaciones, imágenes y tarjetas para introducir, ilustrar y trabajar el contenido respectivamente.

Con respecto a los ejercicios que comprenden el corpus, el factor clave para determinar la viabilidad de su creación o adaptación no fue la finalidad lingüística concreta que perseguían (como practicar gramática, vocabulario o alguna destreza lingüística), sino el tipo de respuesta que planteaba cada uno. En este sentido, y de acuerdo con las distintas funciones que ofrece un procesador de texto (distribuir la información en columnas, crear tablas, enumerar, insertar imágenes, recursos gráficos...), se distinguen dos categorías: ejercicios de resolución cerrada y de resolución abierta.

Siguiendo las definiciones del Diccionario de términos clave de ELE del Centro Virtual Cervantes (CVC), los ejercicios de resolución cerrada son aquellos que normalmente solo se pueden resolver de una única forma correcta, aunque en algunos casos puede haber un número muy limitado de respuestas correctas posibles. Como contraparte, las actividades de resolución abierta son aquellas que se pueden resolver de múltiples formas correctas. En este tipo de actividades, las respuestas correctas posibles son tan numerosas que no se pueden predecir con antelación.

El corpus de estudio incluyó un total de 212 actividades, de las cuales 161 fueron de resolución cerrada y 51 de resolución abierta. En ambos casos, una parte de los ejercicios exigía una respuesta escrita y, la otra parte, una respuesta oral (véase Imagen 2 ).

\footnotetext{
${ }^{12}$ Se usó la herramienta «Canva» por la diversidad de opciones que ofrece a la hora de crear recursos para las clases, puesto que cuenta con una gran variedad de plantillas, elementos gráficos, fotografías, entre otros. Por consiguiente, no fue necesario recurrir a otras herramientas como banco de imágenes, por ejemplo, para crear los materiales. Enlace: https://www.canva.com/
} 
Imagen 2. Ejemplos de actividades creadas y adaptadas

\begin{tabular}{|c|c|}
\hline $\begin{array}{c}\text { EJERCICIOS DE } \\
\text { RESOLUCIÓN CERRADA }\end{array}$ & $\begin{array}{c}\text { EJERCICIOS DE } \\
\text { RESOLUCIÓN ABIERTA }\end{array}$ \\
\hline RESPUESTA ESCRITA & RESPUESTA ESCRITA \\
\hline Completar tablas & Dejar instrucciones \\
\hline Reformular oraciones & Escribir una carta \\
\hline Relacionar información & Hacer una lista de cosas \\
\hline Rellenar huecos & Tesponder un mensaje de texto \\
\hline Seleccionar la opción correcta & RESPUESTA diálogo o texto \\
\hline RESPUESTA ORAL & Describir una imagen \\
\hline Completar vacíos de información & Dar instrucciones \\
\hline Conjugar verbos & Dar una opinión \\
\hline Construir oraciones & Realizar juegos de rol \\
\hline Enlazar palabras o frases & Responder preguntas \\
\hline Formular preguntas &
\end{tabular}

Fuente: elaboración propia

Posteriormente, la manera más simple que se encontró para organizar el material fue a través de un servicio de alojamiento de archivos en la nube de uso colaborativo. En este caso en concreto, se decidió usar Google Drive ${ }^{13}$ por ser una herramienta ampliamente utilizada e intuitiva. Dentro del Drive se puede almacenar distintos tipos de archivos (doc, jpg, pdf, ppt...) o convertir algunos tipos de archivos a través de otras herramientas de Google. A su vez, estos documentos convertibles de Google se pueden compartir con otros usuarios y editarse en línea. De esta manera, estos archivos se pueden trabajar de manera colaborativa, por ejemplo, entre un profesor y un alumno. El tipo de archivo convertible más utilizado para que los alumnos realicen las actividades, tanto en línea como fuera de línea, fueron los archivos realizados con un procesador de texto.

De este modo, tanto los ejercicios de respuesta escrita como los de respuesta oral pudieron realizarse sin ningún tipo de inconvenientes, dada la naturaleza de los medios tecnológicos utilizados: un programa de videoconferencia para impartir la clase, el cual habilita el canal de comunicación oral; y un servicio de alojamiento de archivos en la nube de uso colaborativo en línea, el cual habilita el canal de comunicación escrita. Además, en este caso, como programa de videoconferencia se usó Zoom, el cual posee la función de "compartir pantalla», por lo que el profesor puede mostrarle al estudiante un documento o ejercicio en concreto para trabajar en clase y el estudiante puede mostrarle al profesor un documento o ejercicio sobre el cual está trabajando. Zoom también cuenta con una pizarra virtual integrada, lo que permite que el profesor, al igual que en una pizarra física, resuelva dudas en el momento.

En suma, para crear y adaptar todas las actividades del corpus e impartir una clase en línea, fue necesario manejar solo cuatro herramientas tecnológicas: un procesador de texto, un programa para diseñar

${ }^{13}$ Enlace: https://www.google.com/intl/es/drive/ 
presentaciones, imágenes y tarjetas, una herramienta de almacenamiento en la nube y de uso colaborativo y un programa de videoconferencia.

Llegado este punto, se puede concluir que prácticamente todo el contenido correspondiente al nivel A1 impartido en las clases presenciales se pudo dictar en las clases virtuales a través de la creación y adaptación de material didáctico digital, siguiendo el procedimiento que se acaba de exponer. A su vez, los distintos tipos de actividades (como rellena huecos, verdadero/falso, opción múltiple, etc.) utilizados en ambas modalidades de clase fueron los mismos. No obstante, un hecho destacable a considerar es que la gran mayoría de los juegos tradicionales (como el bingo, el juego de la memoria, etc.), no pudieron crearse o adaptarse bajo dicho procedimiento, dado que, como se verá en el siguiente apartado, fue necesario recurrir a otro tipo de aplicaciones.

La principal limitación en relación con lo anteriormente descrito fue el factor tiempo, puesto que, para crear y adaptar las actividades correspondientes a cada una de las secuencias didácticas del corpus, en conjunto con el diseño de sus respectivas presentaciones de contenido y de sus tarjetas de vocabulario, se invirtió un promedio de 70 horas de trabajo, mientras que, por el otro lado, los estudiantes tardan un promedio de 10 horas en consumir el material de cada lección.

Para finalizar, creemos que es necesario contar con un buen margen de tiempo o, en el caso de una institución, con varios profesores trabajando de manera coordinada y organizada para crear o trasladar una buena cantidad de material físico en un periodo corto de tiempo. Si a este hecho se le suma que hay una cantidad considerable de estudiantes tomando clases de español en distintos niveles o en distintos tipos de cursos, como español con fines específicos, preparación de exámenes, etc., el tiempo requerido será mucho mayor, ya que habrá que crear o adaptar material didáctico diferente para cada caso en cuestión.

\subsection{Incorporación de juegos y actividades interactivas}

Como se ha mencionado en el apartado anterior, con solo aprender a utilizar cuatro herramientas digitales es posible crear y adaptar gran parte del material didáctico e impartir una clase virtual. Sin embargo, para incorporar presentaciones animadas, cuestionarios interactivos y los juegos que tradicionalmente se usan en una clase de español, es necesario aprender a usar algunas herramientas más.

De las herramientas exploradas ${ }^{14}$ para crear algunas actividades del corpus, unas son más fáciles e intuitivas de usar mientras que otras requieren más tiempo y formación, ya que es necesario conocer funcionalidades más avanzadas para, por ejemplo, insertar en las creaciones efectos especiales (aparecer y desaparecer elementos, rotaciones y giros...), dados virtuales y cronómetro, entre otros.

\footnotetext{
${ }^{14}$ Algunas de las herramientas exploradas fueron: Canva, Formularios de Google, Genially, Jamboard, Kahoot, Learning Apps y Power Point.
} 
A continuación, en la imagen 3, pueden observarse algunas de las actividades de esta naturaleza que pueden realizarse con este tipo de herramientas.

Imagen 3. Ejemplos de juegos que pueden adaptarse

\begin{tabular}{|c|c|}
\hline \multicolumn{2}{|c|}{ JUEGOS Y ACTIVIDADES TRADICIONALES } \\
\hline Adivinanzas & Juegos de la memoria \\
\hline Ahorcados & Laberintos \\
\hline Bingos & Ruletas \\
\hline Crucigramas & Sopas de letras \\
\hline Dominós & Tableros \\
\hline
\end{tabular}

Fuente: elaboración propia

Si bien crear estas actividades tiene un mayor grado de complejidad, afortunadamente, las mismas aplicaciones cuentan, cada vez más, con plantillas reutilizables que permiten que el proceso de diseño y creación sea más ágil, simple y accesible para los usuarios con pocas habilidades tecnológicas o escasa competencia digital. Por otra parte, algunos blogs dedicados a la enseñanza-aprendizaje de ELE (véase Méndez Santos, 2016: 45-46) poseen recursos de este tipo que pueden usarse directamente en clase. Un claro ejemplo es el blog de ProfeDeELE ${ }^{15}$.

Para terminar, el contenido del que se dispone en materiales de formato físico se pudo trasladar a un formato digital, ya que existen numerosas herramientas tecnológicas disponibles para tal fin. Además, la gran mayoría de ellas cuenta con un plan o versión gratuita. Si se hace una búsqueda en internet, se encuentra una gran cantidad de aplicaciones para crear todo tipo de actividades, pero muchas veces es difícil saber cuáles escoger o cuáles serían las más adecuadas para determinados propósitos. Para ello, es necesario que el profesorado de ELE se implique en el desarrollo de su propia competencia digital y que esté dispuesto a invertir una buena cantidad de tiempo en formarse y aprender a utilizarlas para aprovechar su potencial didáctico (Instituto Cervantes, 2012: 11).

Por último, la tipología de las actividades que conforman el material utilizado para impartir las clases presenciales y el usado para las clases en línea es muy similar, puesto que el gran cambio no radica en su contenido sino en la forma de presentarlo y trabajarlo en un espacio virtual.

\footnotetext{
${ }^{15}$ ProfeDeELE, como el mismo sitio web se define, es un portal para estudiantes y profesores de español como lengua extranjera con una gran variedad de ideas, recursos y actividades prácticas, publicadas de forma libre, gratuita y que priman la creatividad, la originalidad y la calidad. Enlace: https://www.profedeele.es/
} 


\section{Cuestionario}

En este apartado se darán detalles acerca de la confección del cuestionario, como así también de la muestra obtenida. Posteriormente, se hará un análisis de los resultados, los cuales se cotejarán con los datos recabados en el estudio del corpus lingüístico.

\subsection{Instrumento, distribución y recolección de datos}

El cuestionario ${ }^{16}$ se dividió en cinco secciones: «Presentación», «Antes de la pandemia», "Antes de la pandemia y actualmente», "Pasar de la modalidad presencial a la modalidad en línea» e «Información adicional». La gran mayoría de las preguntas de todas las secciones, más del $90 \%$, consistieron en preguntas que exigían algún tipo de respuesta cerrada, de modo que el estudio fue más bien de corte cuantitativo que cualitativo. La encuesta fue breve, con un tiempo de respuesta de unos 7 minutos aproximadamente.

En la sección 1, se presentaba el título del cuestionario, el objetivo, el anonimato, el tiempo de respuesta aproximado y el contacto de la investigadora. En la sección 2, se pedía información sobre el tipo de clases en línea que habían dado antes de la pandemia. En la sección 3, tenían que contestar una serie de preguntas relacionadas con el conocimiento de herramientas digitales, tanto antes de la pandemia como en el momento presente. En la sección 4, había una tanda de preguntas más generales sobre el traspaso de la modalidad presencial a la modalidad en línea y otras más específicas concernientes a la adaptación del material didáctico. Por último, en la sección 5, las preguntas eran de factores demográficos y de algunas cuestiones generales, tales como el país y el contexto educativo en el que trabajaban.

El cuestionario fue sometido a juicios de expertos antes de ser lanzado para la recolección de datos, validándose así el contenido (Lacave Rodero et al., 2015: 37), dado que se hicieron las correcciones pertinentes según la retroalimentación obtenida. Posteriormente, la encuesta fue publicada en distintas redes sociales y enviada por correo electrónico a distintas listas de distribución de profesores de español. Las respuestas se recogieron desde el 1 de julio de 2021 hasta el 27 de septiembre de 2021 inclusive.

\subsection{Muestra obtenida}

La muestra abarca un total de 102 informantes $y$, aunque es difícil saber la cantidad de informantes necesarios para garantizar la representatividad, el tamaño de la muestra y los datos recabados pueden considerarse significativos, dado el carácter exploratorio del estudio y el resultado contundente de algunos datos recogidos.

\footnotetext{
${ }^{16}$ Enlace: https://forms.gle/nZNwfddchaH3ttmQ8
} 
Con respecto a algunos atributos demográficos de los informantes, estos coinciden ampliamente con el perfil general del profesorado del sector (véase Muñoz-Basols et al., 2017: 2-4). Más de un 35\% se ubica en la franja etaria de los 26 a 35 años, le siguen con más de un 24\% los de 36 a 45 años, y con casi un $18 \%$ los de 46 a 55 años, ubicándose así en estas tres franjas etarias más del $75 \%$ de los encuestados. La gran mayoría son mujeres, concretamente el $77,5 \%$, frente a un $18,6 \%$ de hombres y a un $3,9 \%$ que prefirió no declararlo.

En relación con el contexto educativo en el que estos profesionales desarrollan su labor docente, si bien se podía seleccionar más de una opción, el grupo más numeroso es el que dicta clases particulares, que arrojó un $52,9 \%$ del total, por detrás se sitúa un $38,3 \%$ que trabaja en algún tipo de institución de enseñanza reglada. Por último, se ubican los que trabajan en una escuela de español para extranjeros o en una academia de idiomas con el $32,4 \%$ y el $23,5 \%$ respectivamente. Solo un $3 \%$ mencionó trabajar en alguna otra categoría.

De acuerdo con el país en el que trabajan, un $62,7 \%$ declaró trabajar en un país hispanohablante, es decir en un contexto de inmersión lingüística, frente a un $37,3 \%$ que mencionó trabajar en un país no hispanohablante.

\subsection{Análisis de los datos de la encuesta}

A continuación, se desglosa el análisis de los datos recogidos pertenecientes a las secciones 2,3 y 5 del cuestionario. La sección 1 , como se mencionó en el epígrafe 5.1., corresponde a la presentación y la sección 5 a datos de carácter general que fueron analizados en el epígrafe 5.2. "Muestra obtenida».

\subsubsection{Sección 2: «Antes de la pandemia»}

En esta sección se preguntaba acerca de la experiencia sobre los distintos tipos de clases en línea brindadas antes de la pandemia. Con respecto a esto, más del $62 \%$ de los informantes declaró no haber dado clases particulares en línea antes de la COVID-19, frente a más del 90\% que indicó no haber impartido clases grupales. Por otra parte, solo un 14,7\% manifestó haber dado clases híbridas. Con estos resultados se evidencia un elevado porcentaje de profesores que nunca había incursionado en el mundo de las clases en línea antes de iniciarse la pandemia.

\subsubsection{Sección 3: «Antes de la pandemia y actualmente»}

En relación con los resultados de esta sección donde se indaga sobre el conocimiento de algunas herramientas digitales, más del $90 \%$ mencionó conocer un programa de videoconferencia antes de la pandemia; así, se puede llegar a suponer que la experiencia de haber tenido una sesión en 
línea y en vivo era, al menos en algún aspecto, algo conocida por estos profesionales.

Sobre las herramientas de uso colaborativo en línea, los porcentajes correspondientes a antes y después de la COVID-19 son de 89,2\% y 96,1\% respectivamente. Por consiguiente, la diferencia no es tan significativa, ya que es menor de 7 puntos. De considerarse la manera en la que se traspasó el material didáctico para su estudio, que fue, en gran parte, a través de una herramienta de este tipo, se puede decir que la gran mayoría de los profesores estaba, de algún modo, preparado para hacerlo.

En cuanto al conocimiento de herramientas digitales con funciones más específicas, antes y después de la pandemia, es donde se encuentra el gran salto de conocimiento de los docentes del sector, puesto que hay una brecha bastante considerable en los porcentajes de la gran mayoría de las categorías propuestas, a excepción de la categoría "programas para hacer presentaciones» donde el porcentaje se mantiene prácticamente igual. Cabe aclarar que en esta pregunta se podía seleccionar más de una opción. En el siguiente gráfico (Imagen 4) se puede apreciar el crecimiento.

Imagen 4. Conocimiento de herramientas digitales específicas antes y después de la COVID-19

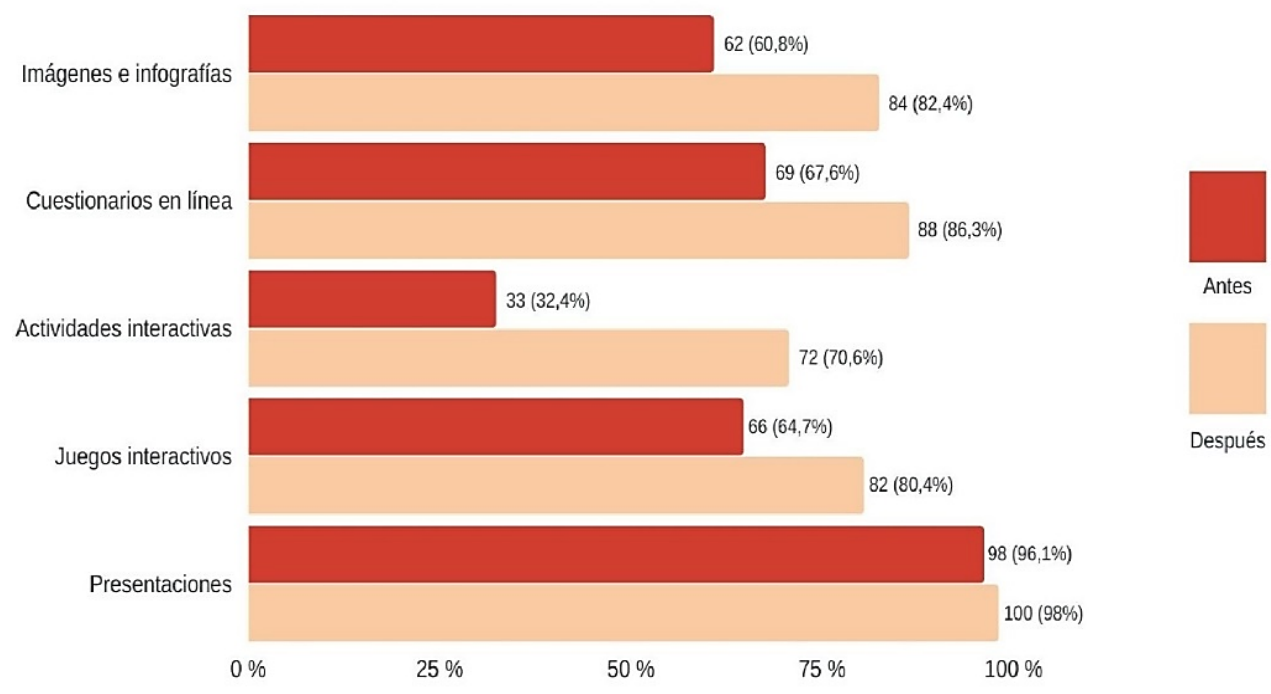

Fuente: elaboración propia

A la vista de estos resultados, se desprende que la gran mayoría de los profesores estaba familiarizado con un programa de videoconferencia, una herramienta de almacenamiento en la nube y de uso colaborativo en línea y un programa para hacer presentaciones. Con dichos conocimientos, contaban con las herramientas básicas y necesarias para impartir una clase en línea y para crear o adaptar gran parte del material didáctico. 


\subsubsection{Sección 4: «Pasar de la modalidad presencial a la modalidad en línea»}

Las preguntas de esta sección pretendían conocer el grado de preparación de los profesores al moverse a la modalidad virtual, los principales inconvenientes con los que se encontraron, como así también obtener respuestas acerca de cuestiones más concretas sobre la adaptación del material didáctico.

Con respecto al grado de preparación, un $49 \%$ indicó haber estado poco preparado y un $16,7 \%$ manifestó haber estado nada preparado. En otras palabras, más del $65 \%$ sintió no tener la preparación suficiente para trasladarse a las clases en línea, contra un $29,4 \%$ que dijo estar suficientemente preparado y solo un $4,9 \%$ muy preparado. A la luz de estos resultados, se evidencia que gran parte de estos profesores sintió una carencia de formación relacionada con las TIC (Tecnologías de la Información y la Comunicación) aplicadas a la educación (véase Muñoz-Basols et al., 2017: 16-17).

Acerca del principal inconveniente que encontraron al pasarse a dar clases en línea en un tiempo récord, más de $52 \%$ seleccionó la opción relacionada con la adaptación del material, le sigue un 15,7\% que marcó la opción de no disponer de un espacio acondicionado en su hogar, y un $12,7 \%$ que no sabía por qué programa de videoconferencia decidirse. Un 4,9\% se inclinó por la opción de «ninguna» y menos de un $15 \%$ seleccionó o expresó otras opciones. Estos resultados dejan entrever que la creación o adaptación del material didáctico se percibió como una cuestión importante, y a la vez problemática, al momento de trasladarse a la virtualidad.

En cuanto a si piensan que existen diferencias entre el material que usan para sus clases presenciales y el que usan en sus clases en línea, un $63,7 \%$ expresó que sí frente a un 36,3\% que dijo lo contrario. En la siguiente imagen (Imagen 5) están plasmadas algunas respuestas de los informantes en relación con los motivos que mencionaron.

Imagen 5. Para ti, ¿existen diferencias entre el material que usas para tus clases presenciales y el que usas para tus clases en línea?

\begin{tabular}{|l|c|}
\hline \multicolumn{2}{|c|}{ EJEMPLOS DE INFORMANTES QUE RESPONDIERON POSITIVAMENTE } \\
\hline INFORMANTE & RESPUESTA \\
\hline Informante 1 & "No se puede improvisar mucho, sobre todo con respecto a los juegos [...]". \\
\hline Informante 16 & "La comunicación es diferente porque el contexto es distinto". \\
\hline Informante 17 & "Exige más dinamismo para compensar la falta de presencialidad y [...]". \\
\hline Informante 82 & "[...] la atención de los alumnos en línea es diferente". \\
\hline Informante 102 & "Porque la interacción entre los alumnos no es la misma". \\
\hline EJEMPLOS DE INFORMANTES QUE RESPONDIERON NEGATIVAMENTE \\
\hline INFORMANTE & \multicolumn{1}{|c|}{ RESPUESTA } \\
\hline Informante 25 & "Porque por suerte he podido adaptarlo todo". \\
\hline Informante 49 & "Porque todo se puede digitalizar". \\
\hline Informante 54 & "Es el mismo, solo que se adapta en archivos digitales". \\
\hline Informante 58 & "Las diferencias son de forma, no de fondo". \\
\hline Informante 90 & "Uso el mismo material pero lo explico y lo exploto de manera distinta". \\
\hline
\end{tabular}

Fuente: elaboración propia 
No obstante, como se puede observar, los encuestados que encuentran diferencias no indican cuestiones concretas sobre el material en sí, sino sobre otros aspectos que se integran en una clase de español como, por ejemplo, el dinamismo de las clases, la atención de los alumnos y la interacción entre los estudiantes, entre otros. Estas respuestas nos invitan a pensar otras líneas de investigación a la hora de trasladar las clases al mundo virtual.

Como respuesta a la pregunta sobre qué porcentaje de material piensan que se puede adaptar, un $38,2 \%$ indicó la franja de $71 \%$ a $90 \%$, mientras que un $21,6 \%$ indicó la franja de $51 \%$ a $70 \%$. Estos números demuestran que casi el $60 \%$ de los profesores cree que más del $50 \%$ del material puede adaptarse. Por otra parte, un porcentaje importante, el $20,6 \%$, opina que el $100 \%$ del material puede trasladarse. Dichos resultados coinciden con los de esta investigación, puesto que, como se mencionó en el apartado 4.2., una gran parte del material pudo adaptarse de una manera bastante simple e intuitiva usando tan solo tres herramientas digitales: un procesador de texto, un programa para hacer presentaciones, imágenes y tarjetas y una herramienta de almacenamiento en la nube y de uso colaborativo.

Ante la pregunta sobre qué tipo de actividades fueron las más difíciles de adaptar, si bien se podía seleccionar más de una opción en las respuestas, los juegos representan casi un 55\%, mientras que, en el resto de las opciones, como actividades de gramática, vocabulario, destrezas lingüísticas y pronunciación, los porcentajes varían entre el $10 \%$ y el $23 \%$. En el siguiente gráfico (Imagen 6) pueden observarse las respuestas.

Imagen 6. Tipos de actividades y grado de dificultad en su adaptación

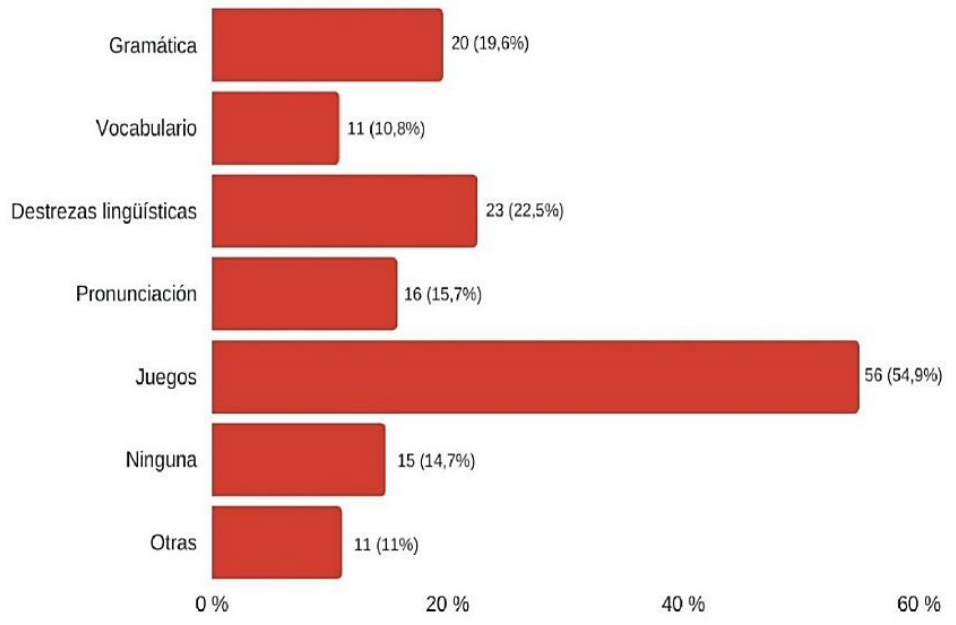

Fuente: elaboración propia

Este dato concuerda ampliamente con lo analizado en este estudio, dado que, para crear o adaptar juegos tradicionales es necesario, en primer lugar, conocer herramientas digitales específicas $y$, en segundo lugar, invertir una 
buena cantidad de tiempo en dominarlas, para luego estar en condiciones de diseñar actividades variadas.

Lo expuesto con anterioridad está vinculado directamente con las respuestas a la pregunta sobre cuál fue la principal limitación a la hora de adaptar el material, donde el ítem "falta de tiempo» arroja más de un 50\%, frente a casi un $27 \%$ del ítem "poco conocimiento de herramientas y aplicaciones tecnológicas específicas», quedando así el resto de las opciones con porcentajes inferiores al 10\%, entre ellas la opción de «escasa competencia digital en general» y la opción «ninguna».

En síntesis, un porcentaje importante de docentes, más del $65 \%$, sintió no estar preparado para moverse a la modalidad virtual en un tiempo récord y más del $50 \%$ sostuvo que el principal inconveniente fue la adaptación del material. Por otra parte, si bien más del 63,7\% expresó que encuentra diferencias entre el material didáctico que utiliza para las clases presenciales y el que usa para las clases en línea, no se brindaron razones exclusivamente concernientes al material en sí, sino que más bien se expresaron motivos que se derivan de una actividad en concreto como, por ejemplo, la interacción entre los estudiantes. Sin embargo, casi un $60 \%$ de los profesores piensa que más de un $50 \%$ del material puede adaptarse y que una de las actividades más difíciles de adaptar son los juegos, que arrojan casi un $55 \%$ comparado con otro tipo de actividades. Por último, en cuanto a las limitaciones, la falta de tiempo supera ampliamente el resto de las categorías, con más del $50 \%$ del total.

\section{Alcances y limitaciones de la investigación}

Aunque la elaboración de la totalidad del corpus y su posterior estudio se realizó con secuencias didácticas correspondientes al nivel A1 del MCER, donde los estudiantes poseen un menor dominio del idioma, como se abarcó el nivel completo, consideramos que los resultados pueden extrapolarse al resto de los niveles $(A 2, B 1, B 2, C 1 \text { y } C 2)^{17}$. Las principales diferencias radicarían en el grado de complejidad de la lengua que exige cada uno de ellos a la hora de plantear una actividad, más que en cuestiones tecnológicas para crear o adaptar el material a un formato digital.

Asimismo, en cuanto a contenido se refiere, la totalidad del corpus se elaboró con ejercicios de español general, puesto que más del $70 \%$ de los estudiantes opta por un curso general de lengua y cultura frente a otros tipos de contenidos (FEDELE, Informe Sectorial 2018: 23). Sin embargo, como una de las cuestiones clave para crear o adaptar una actividad en un formato digital es el tipo de respuesta que cada una exige (de resolución cerrada o de resolución abierta), los resultados podrían extrapolarse también a otro tipo de contenidos como, por ejemplo, español con fines específicos o preparación de exámenes, entre otros.

\footnotetext{
17 Para una descripción detallada de los niveles, véase "Cuadro 1. Niveles comunes de referencia: escala global», en el MCER (Consejo de Europa, 2002: 26).
} 
Por último, como se expuso en el epígrafe 4.1., todas las pruebas que se realizaron en este estudio se hicieron con clases particulares. Sin embargo, creemos que el procedimiento podría adaptarse para el trabajo en clases grupales. En este caso, habría que tener en cuenta que el programa de videoconferencia escogido permita conexiones grupales y conformación de grupos de estudiantes para que puedan trabajar en parejas o en equipo. Con respecto al almacenamiento de los documentos en Google Drive, habría que hacer una copia para cada estudiante y compartírsela, así cada uno puede editar el documento en línea. Por este motivo, tal vez sería más conveniente añadir una plataforma LMS $^{18}$ (Learning Management System) para alojar el material, ya que posee funciones específicas para diseñar aulas virtuales y sería una opción más adecuada para gestionar grupos de alumnos.

En relación a las limitaciones, el presente estudio se centró solo en analizar algunas posibilidades para la digitalización, adaptación o creación de material didáctico exclusivamente, pero no abarcó otras cuestiones que se desprenden directamente del material al Ilevarlo a una clase de ELE, como son, entre otras, las instrucciones para que los estudiantes realicen los ejercicios, la temporización de las actividades, las dinámicas de grupo, y el tipo de corrección que se deriva de cada ejercicio en concreto.

Por otra parte, este estudio solo se ha enfocado en el papel del profesor, pero queda aún por indagar asuntos referentes a los propios estudiantes, los auténticos protagonistas de una clase. Esto nos invita a reflexionar sobre otras líneas de investigación al trasladarnos al mundo virtual.

\section{Conclusiones}

Por una parte, para crear y adaptar gran parte del material didáctico para impartir una clase particular en línea y en vivo es necesario conocer, al menos, cuatro herramientas digitales. Por otra parte, para dar clases en línea grupales y organizar el material de estudio, si bien contar con un servicio de alojamiento en la nube es de gran ayuda, sería más práctico y beneficioso sumar una plataforma LMS, debido a la serie de ventajas con las que cuenta para gestionar grupos de alumnos.

Con respecto al material que se utiliza en las clases presenciales y en línea, se concluye que no hay diferencias considerables, puesto que el formato, ya sea físico o digital, no afecta la tipología de las actividades. También, se llega a la conclusión de que prácticamente todo el contenido puede trasladarse (ya sea creándolo o adaptándolo), incluso los juegos, aunque para estos últimos hay que aprender a utilizar aplicaciones extra y, en algunos casos, conocer funcionalidades avanzadas.

18 Un ejemplo de estas plataformas y una de las más utilizadas es Moodle. Enlace: https://moodle.org/?lang=es Si se quisieran integrar todos los servicios de Google, se podría usar Classroom. Enlace: https://edu.google.com/intl/es$419 \mathrm{ALL} /$ products/classroom/ 
En cuanto a las limitaciones encontradas a la hora de crear o adaptar el material, la falta de tiempo fue el factor principal. Esto tiene su lógica, puesto que es necesario invertir una cantidad considerable de tiempo, no solo para crear o adaptar el material, sino también para descubrir las herramientas digitales apropiadas, explorarlas y familiarizarse con ellas.

Para terminar, los docentes de ELE estaban bastante preparados en el momento de iniciarse la pandemia, dado que la gran mayoría conocía las herramientas digitales básicas para trasladarse a la virtualidad. No obstante, como bien indicaron ellos mismos en la encuesta (más del 90\%), si bien aprendieron mucho durante este periodo, consideran que es necesario seguir formándose para potenciar su competencia digital.

\section{Bibliografía}

Consejo De Europa (2002): Marco común europeo de referencia para las lenguas: aprendizaje, enseñanza, evaluación. Madrid: Secretaría General Técnica del MEC, Anaya e Instituto Cervantes. https://cvc.cervantes.es/ensenanza/biblioteca ele/marco/

Fedele (2018): Español en España. Informe sectorial 2018. https://fedele.org/estudios-e-informes/

InStituto CeRVANTES, Centro Virtual Cervantes (CVC) (en línea): Diccionario de términos clave de ELE, "Resolución abierta". https://cvc.cervantes.es/ensenanza/biblioteca ele/diccio ele/dicci onario/resolucionabierta.htm

InStITUto CeRVANTES, Centro Virtual Cervantes (CVC) (en línea): Diccionario de términos clave de ELE, "Resolución cerrada". https://cvc.cervantes.es/ensenanza/biblioteca ele/diccio ele/dicci onario/resolucioncerrada.htm

Instituto Cervantes, Centro Virtual Cervantes (CVC) (en línea): Diccionario de términos clave de ELE, "Secuencia didáctica". https://cvc.cervantes.es/Ensenanza/biblioteca ele/diccio ele/dicci onario/secuenciadidactica.htm

INSTITUTO CERVANTES (2012): "Las competencias clave del profesorado de lenguas segundas y extranjeras". https://cvc.cervantes.es/ensenanza/biblioteca_ele/competencias/d efault.htm

InSTITUTO CERVANTES (2006): Plan curricular del Instituto Cervantes. Niveles de referencia para el español. Madrid: Biblioteca Nueva. http://cvc.cervantes.es/ensenanza/biblioteca ele/plan curricular/d efault.htm

Lacave Rodero, C.; Molina díaz, A. I.; Fernández Guerrero, M. y Redondo Duque, M. Á. (2015): "Análisis de la fiabilidad y validez de un cuestionario docente", en Actas de las XXI Jornadas de la Enseñanza Universitaria de la Informática, Universitat Oberta: Universitat Oberta La Salle, pp. 136-143.

https://upcommons.upc.edu/handle/2117/76844?show=full 
LITTLEWOOD, W. (1981): La enseñanza comunicativa de idiomas. Cambridge: Cambridge University Press.

MARTín PERIS, E. (1996): Las actividades de aprendizaje en los manuales para la enseñanza de Español como Lengua Extranjera (E/LE). Tesis doctoral. Universitat de Barcelona.

https://www.tdx.cat/handle/10803/286731\#page=1

MÉNDEZ SANTOS, M. del C. (2016): Guía para profesorado de español como lengua extranjera (ELE) 6.0. http://mariamendezsantos.com/?p=795

Muñoz-BAsols, J.; Rodríguez-Lifante, A. y CRuz-Moya, O. (2017): “Perfil laboral, formativo e investigador del profesional de español como lengua extranjera o segunda (ELE/EL2): datos cuantitativos y cualitativos", Journal of Spanish Language Teaching, vol. 4, no 1, pp. 1-34. http://dx.doi.org/10.1080/23247797.2017.1325115

ORganización Mundial De La SALUd (2020): “Alocución de apertura del Director General de la OMS en la rueda de prensa sobre la COVID-19 celebrada el 11 de marzo de 2020". https://www.who.int/es/director-general/speeches/detail/whodirector-general-s-opening-remarks-at-the-media-briefing-on-covid19---11-march-2020

ORganización Mundial De La SALUd (2020): “Cronología de la respuesta de la OMS a la COVID-19". Comunicación de prensa. Organización Mundial de la Salud. https://www.who.int/es/news/item/29-06-2020covidtimeline 